\title{
Understanding handwriting difficulties: A comparison of children with and without motor impairment
}

\section{Mellissa Prunty \& Anna L. Barnett}

To cite this article: Mellissa Prunty \& Anna L. Barnett (2017) Understanding handwriting difficulties: A comparison of children with and without motor impairment, Cognitive Neuropsychology, 34:3-4, 205-218, DOI: 10.1080/02643294.2017.1376630

To link to this article: https://doi.org/10.1080/02643294.2017.1376630

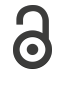

(C) 2017 The Author(s). Published by Informa

UK Limited, trading as Taylor \& Francis Group

册 Published online: 26 Sep 2017.

Submit your article to this journal

Џll Article views: 451

Q View related articles $\sqsubset$

View Crossmark data \lceil

Citing articles: 1 View citing articles 


\title{
Understanding handwriting difficulties: A comparison of children with and without motor impairment
}

\author{
Mellissa Prunty (i) $^{a}$ and Anna L. Barnett ${ }^{b}$ \\ ${ }^{\mathrm{a} D}$ Department of Clinical Sciences, Brunel University London, Uxbridge, UK; ${ }^{\mathrm{b}}$ Oxford Brookes University, Oxford,UK
}

\section{ABSTRACT}

The nature of handwriting difficulties have been explored in children with specific developmental disorders. The aim of this study was to investigate the nature of handwriting difficulties in children with dysgraphia, a less studied group who have significant handwriting difficulties in the absence of motor control or cognitive difficulties. The performance of a dysgraphia group aged 8-14 years was compared to a group with Developmental Coordination Disorder and to typically developing (TD) controls. Participants completed two handwriting tasks on a digitizing writing tablet. The amount and accuracy of the handwriting product was measured, plus various temporal and spatial features of the writing process. There were no significant differences in performance between the two groups with handwriting difficulties but both performed more poorly than the TD group. Individual differences in the type and severity of handwriting impairments suggest the need for a range of classroom assessments to tailor intervention appropriately.
ARTICLE HISTORY

Received 6 March 2017

Revised 29 August 2017

Accepted 30 August 2017

\section{KEYWORDS}

Developmental coordination disorder; dysgraphia; handwriting speed; pausing; writing

\section{Introduction}

The skill of handwriting is an important gateway to academic success (Graham, Berninger, Weintraub, \& Schafer, 1998) as it supports participation in the classroom and provides a valuable source of self-esteem in children (Engel-Yeger, Nagauker-Yanuv, \& Rosenblum, 2009). It is a complex skill, often referred to as "language by hand" (Berninger, Abbott, Abbott, Graham, \& Richards, 2002), which reflects the complex integration of cognitive and motor processes that underpin the task (Van Galen, 1991). As such, handwriting skill takes time to develop (Barnett, Henderson, Scheib, \& Schulz, 2007; Graham et al., 1998). Initially, correct letter formation (including size and shape) are taught in the classroom (5-6 years; Department for Education, DfE, 2013) followed by an emphasis on speed and fluency later on (8-9 years of age; DfE, 2013). The development of handwriting speed in particular plays an important role in the overall task of writing, as the number of words produced per minute has been found to predict compositional quality in both typically (Graham, Berninger, Abbott, Abbott, \& Whitaker, 1997; Puranik \& Al Otaiba, 2012) and atypically developing children (Connelly, Dockrell,
Walter, \& Critten, 2012; Prunty, Barnett, Wilmut, \& Plumb, 2016; Sumner, Connelly, \& Barnett, 2014). Therefore, if a child has difficulties with aspects of handwriting performance such as speed and/or legibility, it can significantly hamper progress in the classroom and lead to academic underachievement (Graham, Harris, \& Fink, 2000).

According to Van Hartingsveldt, De Groot, Aarts, and Nijhuis-Van Der Sanden (2011) up to $27 \%$ of school-aged children experience difficulties with handwriting. Handwriting difficulties are varied in their presentation and may be explained by a range of factors. Van Galen's (1991) psychomotor model of handwriting can provide a useful lens for considering handwriting difficulties in children, as it describes the range of cognitive and motor processes involved in the skill. At the top level, Van Galen (1991) refers to higher level cognitive processes including attention (activation of the intention to write) and language (semantic retrieval and syntactical construction). These processes have been linked to poor handwriting in children with various developmental disorders including attention deficit hyperactivity disorder (ADHD; Adi-Japha et al., 2007; Rosenblum, Epsztein, 
\& Josman, 2008) and specific language impairment (SLI; Connelly \& Dockrell, 2015; Connelly et al., 2012). In children with SLI, for example, language ability was found to constrain handwriting speed and fluency (Connelly \& Dockrell, 2015; Connelly et al., 2012) as they produced fewer words per minute and paused for longer during writing than typically developing peers.

Below the levels of language, Van Galen (1991) describes the process of spelling. This can be programmed in two ways: through the mapping of phoneme-to-grapheme (sound to letter) rules or through knowledge of spelling a familiar word (orthographic representations; Miceli \& Capasso, 2006; Rapp, Purcell, Hillis, Capasso, \& Miceli, 2016). Indeed spelling difficulties, found in children with dyslexia, have been linked to poor handwriting performance. Sumner, Connelly, and Barnett (2013) found that children with dyslexia produced fewer words per minute than typically developing peers. By analysing the location of writing pauses, Sumner et al. (2013) revealed that the dyslexic group had a tendency to pause within misspelled words, which impacted on their handwriting speed. However, the notion of spelling as a constraint on handwriting also applies to typically developing individuals where word-structure has been found to mediate the kinematics of handwriting (Kandel, Soler, Valdois, \& Gros, 2006). For example, the process of phoneme to grapheme mapping can constrain handwriting speed (Kandel et al., 2006), as can the number of syllables in a word (Lambert, Kandel, Fayol, \& Esperet, 2008). It is therefore apparent that language and spelling are important components to consider when examining handwriting difficulties in children, as these factors alone can constrain performance.

According to Van Galen's (1991) model, there are three motor processes involved in handwriting production. The first is the selection of the allograph, ${ }^{1}$ which according to Van Galen's model refers to the activation of the motor programme (retrieval of an action pattern from long-term motor memory) and the selection of the type of script (joined, un-joined, capital letters, small letters). Following this, the parameterization process occurs under size control where the size, speed, and spacing of allographs are programmed (Van Galen, 1991). This is followed by recruitment of muscle synergies, which results in the real-time movement of the pen (Van Galen, 1991). These three motor processes (selection of allograph, size/speed control, muscular adjustment) are complex in nature, and any one may be associated with handwriting difficulties. One population known for their difficulties with motor skill are children with developmental coordination disorder (DCD; American Psychiatric Association, APA, 2013). DCD is the term used to describe children who have motor coordination difficulties that are unexplained by a general medical condition, intellectual disability, or neurological impairment (APA, 2013). They commonly present with slow and poorly formed handwriting (Prunty, Barnett, Wilmut, \& Plumb, 2014; 2016; Rosenblum \& Livneh-Zirinski, 2008) and have a tendency to pause for a greater percentage of writing tasks than typically developing peers (indicating a lack of automatization; Prunty et al., 2014). They also produce a higher percentage of errors during the process of letter formation including incorrect starting position and inaccuracy in the number, direction, and sequence of letter strokes (Prunty and Barnett, 2017). These difficulties appear to straddle the three motor processes in Van Galen's model.

Van Galen's model is useful in outlining the processes involved in the skill of handwriting and, as outlined above, how these are impacted by cognitive or motor impairments associated with developmental disorders. However, teachers also commonly report handwriting difficulties in children in the absence of motor or cognitive impairment, and these have been referred to by some as "dysgraphia" (Di Brina, Niels, Overvelde, Levi, \& Hulstijn, 2008; Dohla \& Heim, 2015; Rosenblum, Parush, \& Weiss, 2003; Smits-Engelsman \& Schoemaker, 2017). This term is not formally described in either of the international classification systems, Diagnostic and Statistical Manual of Mental Disorders-Fifth Edition (DSM-5) or International Classification of Diseases-10th Revision (ICD-10) but the literal translation of the Greek term is "bad writing", which includes handwriting, spelling, and written expression. While "dysgraphia" has been used by some to describe children with spelling difficulties (e.g., Miceli \& Capasso, 2006), many have used the term to denote children with handwriting difficulties (e.g., Di Brina et al., 2008; Dohla \& Heim, 2015; Rosenblum et al., 2003; Smits-Engelsman \& Schoemaker, 2017), and that is the focus of the current paper. Studies that have focused on handwriting performance in children with dysgraphia reported difficulties such as slow and illegible handwriting with a tendency to pause during writing (Rosenblum et al., 2003). Although this seems 
very similar to features of handwriting in $D C D$, no study has directly compared handwriting performance across these groups. Smits-Engelsman and Schoemaker (2017) found no differences between a DCD and "dysgraphia" group on a drawing task, in which children copied a series of patterns from a computer screen as quickly and accurately as possible. Although both groups had slower movement velocity, had a smaller trajectory length, and were less accurate than typically developing controls, the DCD and "dysgraphia" groups did not differ from each other. However, the results may be quite different for a handwriting task involving the production of language by hand. In previous research, distinctions between the handwriting difficulties of children with different developmental disorders suggest different approaches to intervention for these groups. In the same vein, further investigation of those with dysgraphia is needed to inform tailored interventions for these children.

While previous studies tend to focus on group findings, the heterogeneity of groups is acknowledged, and it is recognized that individual differences may be masked (Sugden \& Chambers, 2007). Moreover, handwriting difficulties can take various forms, as mentioned above, and children may have different profiles of proficiency across various temporal and spatial measures of handwriting performance (e.g., letter accuracy, legibility, pausing, and overall speed). Therefore, the main aim of this study was to examine handwriting performance in children with dysgraphia (handwriting difficulties), compared to children with DCD (general motor difficulties) and a typically developing control group using tools commonly used by teachers and health professionals in an attempt to tap into the motor processes outlined in Van Galen's (1991) model. Measures of the handwriting product (speed and legibility) were supplemented with more detailed temporal aspects (process measures) of performance across two handwriting tasks. Group analyses were supplemented with an examination of individual performance profiles within and across the three groups.

\section{Method}

Two groups of children with handwriting difficulties were included, a dysgraphia and a DCD group. Handwriting difficulties were determined by scores either below the 15th percentile on the Detailed Assessment of Speed of Handwriting (DASH; Barnett et al., 2007), indicating slow handwriting, or below average on the Handwriting Legibility Scale (HLS; Barnett, Prunty, \& Rosenblum, 2013).

\section{Participants}

Twenty-eight children with handwriting difficulties were recruited to the study, ranging from 8 to 14 years of age. For 14 of these children their handwriting difficulties were accompanied by a diagnosis of DCD (14 boys); the remaining 14 had handwriting difficulties with no significant motor impairment (dysgraphia group). There was a third group of 14 typically developing children (TD group) with neither handwriting difficulties nor movement difficulties. All three groups were age and gender matched in the study. The recruitment procedure for each group is outlined below.

\section{Dysgraphia group}

This group was recruited through local primary and secondary schools. Teachers were asked to use their professional judgement to identify children with handwriting difficulties without motor, reading/spelling difficulties and without intellectual impairment. The children were also individually tested on the Movement Assessment Battery for Children 2nd edition Test (MABC-2 Test; Henderson, Sugden, \& Barnett, 2007), British Picture Vocabulary Scale 2nd edition (BPVS-2; Dunn, Dunn, Whetton, \& Burley, 1997), and the reading and spelling components of the British Ability Scales 2nd Edition (BAS-Il; Elliot, 1996). Children in this group had a MABC-2 score above the 15th percentile and standard scores above 85 on the BPVS and reading/spelling measures, indicating performance within the expected range. None had a diagnosis of dyslexia.

\section{$D C D$ group}

The children with DCD were recruited from a database of children previously assessed and who met the formal diagnostic criteria from the DSM-5 (APA, 2013). The children had significant motor difficulties, with performance below the 10th percentile (13 were below the 5th, 1 below the 10th) on the MABC-2 (Henderson et al., 2007). These difficulties had a significant impact on their activities of daily 
living, as reported by their parents and evident on the MABC-2 Checklist (Henderson et al., 2007). A developmental, educational, and medical history was taken from the parents, which confirmed that there was no history of neurological or intellectual impairment and no medical condition that might explain the motor deficit. The BPVS-2 (Dunn et al., 1997) was used to give a measure of receptive vocabulary, which correlates highly with verbal IQ (Glenn \& Cunningham, 2005). This was in at least the average range (above a standard score of 85 ) for all children. The Strengths and Difficulties Questionnaire (SDQ; Goodman, 1997) was also used to note any other behavioural difficulties reported by the parent, which commonly occur with DCD, such as ADHD (Miller, Missiuna, Macnab, Malloy-Miller, \& Polatajko, 2001). The parent interviews revealed that no children had been given a diagnosis of ADHD from a health professional. The children were also assessed on the reading and spelling components of the BAS-II. None had a diagnosis of dyslexia.

\section{Typically developing (TD) control group}

Teachers in local primary and secondary schools were asked to use their professional judgement to identify children without any handwriting, motor, or reading/ spelling difficulties and without intellectual impairment. To ensure that the children identified were free of these difficulties, they were individually tested on the MABC-2 Test, the BPVS-2, and the reading and spelling components of the BAS-II. Children were included in the control group if they scored at least at the typical level expected for their age on all measures.

\section{Exclusion criteria}

Children from all groups with a diagnosis of dyslexia and/or those who had English as a second language were excluded from the study. Children who had a reported physical, sensory, or neurological impairment or who were born before 35 weeks gestational age were also excluded. This was to ensure that handwriting difficulties could not be attributed to other disorders. See Table 1 for performance profiles of all groups.

\section{Assessments}

The detailed assessment of speed of handwriting (DASH; Barnett et al., 2007)

The DASH is a standardized handwriting speed test with UK norms for 9- to 16-year-olds. It is commonly used among teachers and health care professionals to identify children with handwriting difficulties (Blank, Smits-Engelsman, Polatajko, \& Wilson, 2012). In this study two tasks from the DASH were implemented: alphabet writing and free writing. The demands of both tasks were deemed acceptable for use with children aged 8 years as they align with practice in the classroom and have been successfully used in our previous work (Prunty, Barnett, Wilmut, \& Plumb, 2013, 2014); they are outlined below.

Alphabet writing. The participants wrote the alphabet repeatedly from memory as fast as possible for one minute. They were instructed to write it in the correct order using lower-case letters, making sure that every letter was readable.

Free writing. The participants wrote on the topic of "my life". A spider diagram, offering different writing suggestions, was presented prior to writing, in order to elicit ideas from the child. The content of their writing was not assessed, but they were instructed to try and write continuously over a 10-minute period using their everyday handwriting. They were

Table 1. Mean age and scores for dysgraphia, DCD, and TD groups on selection measures.

\begin{tabular}{|c|c|c|c|c|c|}
\hline Selection measures & $\begin{array}{c}\mathrm{D} \\
(n=14)\end{array}$ & $\begin{array}{c}\text { DCD } \\
(n=14)\end{array}$ & $\begin{array}{c}\text { TD } \\
(n=14)\end{array}$ & $p$ & \\
\hline Age in years & $10.55(1.77)$ & $10.61(1.82)$ & $10.47(2.00)$ & .981 & \\
\hline \multicolumn{6}{|l|}{$M A B C-2$ Test percentiles } \\
\hline Total test score & $32.00(21.15)$ & $6.41(8.12)$ & $48.28(26.32)$ & $<.001^{*}$ & $\mathrm{DCD}<\mathrm{D}<\mathrm{TD}$ \\
\hline Manual Dexterity component & $36.21(24.60)$ & $7.42(9.14)$ & $55.85(30.92)$ & $<.001^{*}$ & $\mathrm{DCD}<\mathrm{D}<\mathrm{TD}$ \\
\hline BPVS-2 standard score & $105.43(11.3)$ & $111.21(17.44)$ & $106.77(12.79)$ & .532 & \\
\hline BAS-II spelling standard score & $104.00(12.78)$ & $100.36(10.58)$ & $112.21(10.11)$ & $.023^{*}$ & $\mathrm{DCD}=\mathrm{D} ; \mathrm{D}=\mathrm{TD} ; \mathrm{DCD}<\mathrm{TD}$ \\
\hline BAS-II reading standard score & $113.80(9.48)$ & $113.71(11.04)$ & $121.86(11.60)$ & .101 & \\
\hline
\end{tabular}


first given one minute to think of some ideas before writing. No instructions were given regarding writing style, and children used their usual way of writing. In the UK there is no single, prescribed writing style; some schools teach fully joined ("cursive") from the start, but a semi-joined script is most common, and this was reflected in our sample.

Performance on these two tasks was scored and analysed in various ways, as described in the "Data Analysis" section below.

\section{The Handwriting Legibility Scale (HLS; Barnett et al.,} 2013)

The HLS examines five different components of handwriting legibility including global legibility (overall readability of the text on first reading), effort to read the script, layout on the page, letter formation, and alterations to writing (attempts made to rectify written work). The HLS is applied retrospectively to the DASH free-writing task. Each component is scored on a scale of 1 to 5 with 1 representing good performance and 5 representing poor performance. Each component is summed to give a total score for legibility with total scores ranging from 5 to 25 , with higher scores reflecting poorer legibility. Inter-rater reliability and internal consistency have been reported to be high ( $a=.92$ in each case), with all components loading on just one factor. The total HLS score for each group is recorded. The analysis involving the HLS is described below.

\section{Apparatus}

When completing the two DASH tasks the participants wrote with an inking pen on paper placed on a Wacom Intuos 4 digitizing writing tablet (325.1 $\mathrm{mm} \times 203.2 \mathrm{~mm}$ ) to record the movement of the pen during handwriting. The writing tablet transmits information about the spatial and temporal data of the pen as it moves across the surface. The data were sampled at $100 \mathrm{~Hz}$ via a laptop computer. Eye \& Pen Version 2 (EP2) software (Alamargot, Chesnet, Dansac, \& Ros, 2006) was used to analyse the tablet data.

\section{Measures}

From the above assessments, a range of measures were obtained, aligned as closely as possible with the motor processes from Van Galen's (1991) model. Although these do not provide a pure measure of each process, they indicate how commonly used clinical tools can be used to begin to examine different components of the model.

\section{Motor Process 1: Selection of the allograph}

\section{Quality of letter formation}

According to Van Galen (1991), the first stage in the motor aspect of handwriting is the selection of the allograph. Using Van Galen's definition of an allograph we examined this process across the three groups. To do so, we examined the quality of letter form production, as this might reflect incomplete (or erroneous) knowledge about the proper form of the allograph. The participants completed the alphabet task from the DASH (Barnett et al., 2007; described above). The alphabet was chosen as it would naturally facilitate an examination of each of the individual letter forms required for handwriting. Using EP2's video function, which allows for the replay of handwriting production in real time on a laptop, the alphabet task was initially played and replayed in slow motion. The video was paused if needed to allow for accurate coding of the process. In the UK children may be taught different handwriting styles, which include variations of joined or un-joined letterforms, so the coding in this study only focused on incorrect letterforms and directions that the children would not be taught in the school system regardless of style.

The quality of letter formation was examined using the following codes.

1. Letter stroke in wrong direction: This occurred in letters that "looked" appropriate on paper but when replayed revealed incorrect letter stroke directions. An example of this was a clockwise rather than anticlockwise direction when forming the letter "a" or "o".

2. Incorrect start place: This occurred if a letter started in a position that would not be taught. An example of this includes the letters " $r$ ", " $n$ ", or "i" starting at the baseline rather than at the top of the letter.

3. Letters with missing strokes: This occurred if a letter was missing a required stoke. An example of this includes the letters " $\mathrm{t}$ " and " $\mathrm{f}$ " without the cross stroke or " $r$ ", " $n$ ", " $u$ " completed with one stroke rather than two.

4. Letters with added strokes: This occurred through over-writing on a letter. An example of this is repeating strokes already formed. 
5. Letter reversals: This occurred if a letter was formed in the opposite direction. An example of this is the letter "b" appearing as " $d$ ".

The percentage of letters in the alphabet task with formation errors was calculated and reported for each group. The inter-rater reliability for this measure is .89 as reported previously in Prunty and Barnett (2017).

\section{Motor Process 2: Size/speed control}

The second motor process outlined in Van Galen's (1991) model is size control, which refers to the parameterization of the allograph. This is where the size, speed, and spacing of allographs are programmed.

\section{Size and spacing}

To examine letter size and spacing we used two measures of legibility on the free-writing task including the HLS total score (as described above) and the percentage of illegible words identified using the instructions from the DASH manual. The HLS score takes into account an overview of both letter size and spacing while the percentage of illegible words provides an additional word-level analysis. While issues with legibility may be attributed to difficulties in other areas (i.e., the level of the allographquality of letter forms), we made the assumption based on Di Brina et al.'s (2008) findings that parameterization including poor spacing and size could also contribute to legibility issues. In their study they reported that difficulties with letter spacing were independent of the difficulties observed in letter form production (Di Brina et al, 2010).

\section{Handwriting speed}

To examine the speed of handwriting the scoring instructions from the DASH manual were applied to the 10-min free-writing task. The number of words per minute were averaged over the 10-min period. Indeed the number of words per minute is a frequently used measure of handwriting speed in the literature on writing (Connelly et al., 2012; Sumner et al., 2013).

\section{Motor Process 3: Muscular adjustment and real- time trajectory of pen}

The final stage described in Van Galen's model is thought to represent the recruitment of muscle synergies and the real-time movement of the pen. We examined this process through the temporal aspects of performance measured using the digitizing writing tablet (as described above) and the EP2 software (Alamargot et al., 2006). In particular, we examined execution speed to explore muscular adjustment and writing pauses to explore any interference with the real-time trajectory.

The following variables obtained from EP2 were ascertained for the alphabet and free-writing tasks:

1. Execution speed $\left(\mathrm{cm} \mathrm{s}^{-1}\right)$ : The speed of the pen when it is in contact and moving on the page. This does not include when the pen is pausing on the page.

2. Pause duration (\% of writing time): The percentage of time during the task where the pen was either off the page (in-air pause), or halted on the page (on-paper pause). A pause was defined as three successive digital samples without movement (a halt $>30 \mathrm{~ms}$ ) (Alamargot et al., 2006). This threshold has been used by other researchers in the case of handwriting in dyslexia, in speech and language impairments, and in typically developing populations (Alamargot et al., 2006; Connelly et al., 2012; Sumner et al., 2013). It is the minimum threshold available with the EP2 software and is thought to capture all writing events.

\section{Individual performance profiles}

In order to ascertain whether the children in the dysgraphia and DCD groups were performing more poorly than TD peers on handwriting measures, the mean and standard deviation from the TD group were used to denote typical or average performance. The number of standard deviations from the TD mean was calculated to demonstrate the severity of difficulties in the dysgraphia and DCD groups in comparison to TD peers. This was calculated for the following measures:

1. Speed: Number of words per minute on the freewriting task.

2. Legibility: Total score of the HLS.

3. Percentage of pausing on the free-writing task.

4. Percentage of errors in letter formation on the alphabet task. 
Initially the numbers and percentages of participants who were poor on each measure (at least below 1 $S D$ of the TD mean) were calculated. A common cutoff to determine poor performance on a measure is more than one standard deviation from the mean (Cascio, Alexander, \& Barrett, 1988). This was then extended across the measures to ascertain the number and percentage of participants who were poor on two and three measures.

\section{Procedure}

The study was approved by the University Research Ethics Committees at Oxford Brookes University and Brunel University London. Parents were required to sign a consent form, and children were asked to either assent (below 11 years) or countersign the parent consent form (over 11 years).

The handwriting component of this study took place over one 60-min session. Each child met with the first author and completed the reading, spelling, and handwriting tasks. The sessions were completed either at the child's home or school or at Oxford Brookes University or Brunel University London. During the handwriting tasks the children were seated at a height-adjustable table and chair, with knees positioned at approximately $90^{\circ}$. The participants were invited to manoeuvre the tablet to a position that was comfortable for them when writing.

\section{Data analysis}

\section{Group differences}

To examine group differences on a range of handwriting measures, one-way analyses of variance (ANOVAs; or non-parametric equivalent) were used. Significant group effects were broken down using pairwise comparisons. An analysis of covariance (ANCOVA) was used with age as a co-variate on handwriting speed and pausing measures due to the relationship between these variables and age and the wide age-range of participants. Two-way mixed ANCOVAs were used to examine group differences across handwriting execution speed. Significant main effects and interactions were broken down using post hoc tests and simple main effects, respectively. For all analyses, significance levels were set at .05 , with Bonferroni corrections used to control for multiple comparisons.

\section{Correlations}

Partial bivariate correlations (controlling for age) were also conducted to examine the relationship between reading/spelling/vocabulary/motor skills and the handwriting measures (quality of letter formation, handwriting speed, legibility, and pausing). The correlations were calculated for each group separately and for all participants together.

\section{Results}

\section{Motor Process 1: Selection of the allograph}

The quality of letter formation

Kruskal-Wallis $H$ tests showed that there was a significant effect of group in the percentage of errors in letter production produced, $\mathrm{X}^{2}(2)=7.37, \quad p=.025$ (mean rank 21.39 for dysgraphia, 27.82 for DCD, 15.29 for TD). Mann-Whitney $U$ tests (with Bonferroni corrections) revealed that the dysgraphia group $(U=$ 42.25. $Z=-2.56, p=.010$ ) performed significantly below the TD group but did not differ from the DCD group $(U=65.0 . Z=-1.52, p=.129$; see Table 2$)$.

\section{Motor Process 2: Size/speed control}

\section{Size and spacing}

Handwriting Legibility Scale. There was a significant effect of group for performance on the HLS, $X^{2}(2)=$ 22.96, $p<.001$ (mean rank 27.61 for dysgraphia, 28.18 for DCD, 8.71 for TD). The TD group demonstrated significantly better performance on the HLS than the dysgraphia $(U=14.0, Z=-3.87, p<.001)$ and DCD $(U=3.00 . Z=-4.38, p<.001)$ groups, which did not differ from each other $(U=96.5 . Z=-0.69$, $p=.945)$.

Percentage of illegible words. Kruskal-Wallis $H$ tests showed that there was a significant effect of group in the percentage of illegible words produced in the DASH free-writing task, $\mathrm{X}^{2}(2)=22.72, p<.001$ (mean rank 27.21 for DCD, 28.18 for dysgraphia, 9.11 for TD). Mann-Whitney $U$ tests (with Bonferroni corrections) revealed that the TD group performed significantly better than both the dysgraphia $(U=7.50$, $Z=-4.44, p<.001)$ and $\mathrm{DCD}(U=15.0, Z=-4.14$, $p<.001)$ groups, which did not differ from each other $(U=95.0, Z=-1.38, p=.890$; see Table 2$)$. 
Table 2. A comparison of the handwriting performance measures for the dysgraphia, DCD, and TD groups.

\begin{tabular}{|c|c|c|c|c|}
\hline Measures & $\begin{array}{c}\text { Dysgraphia } \\
\begin{array}{c}(n=14) \\
M(S D)\end{array}\end{array}$ & $\begin{array}{c}\text { DCD } \\
(n=14) \\
M(S D)\end{array}$ & $\begin{array}{c}\text { TD } \\
(n=14) \\
M(S D)\end{array}$ & \\
\hline \multicolumn{5}{|l|}{ Handwriting product } \\
\hline Alphabet (lpm) & $41.07(23.28)$ & $42.93(16.17)$ & $52.57(15.66)$ & \\
\hline Free writing $(\mathrm{wpm})^{*}$ & $12.43(3.83)$ & $12.34(4.22)$ & $15.38(4.48)$ & $\mathrm{TD}>(\mathrm{D}=\mathrm{DCD})$ \\
\hline HLS (total score)* & $16.57(3.61)$ & $17.64(4.10)$ & $9.57(2.06)$ & $\mathrm{TD}<(\mathrm{D}=\mathrm{DCD})$ \\
\hline \% Illegible words* & $4.98(4.53)$ & $6.55(8.22)$ & $0.001(0.005)$ & $\mathrm{TD}<(\mathrm{D}=\mathrm{DCD})$ \\
\hline \multicolumn{5}{|l|}{ Handwriting process } \\
\hline \multicolumn{5}{|l|}{ Execution speed $(\mathrm{cm} / \mathrm{s})$} \\
\hline Alphabet & $2.63(1.02)$ & $2.46(0.82)$ & $2.74(0.73)$ & \\
\hline Free writing & $2.85(0.61)$ & $2.67(0.63)$ & $2.64(0.61)$ & \\
\hline \multicolumn{5}{|l|}{ Percentage of pausing } \\
\hline Alphabet & $60.74(9.08)$ & $56.94(9.44)$ & $58.28(9.08)$ & \\
\hline Free writing* & $61.20(7.15)$ & $62.19(8.66)$ & $53.52(8.70)$ & $\mathrm{TD}<(\mathrm{D}=\mathrm{DCD})$ \\
\hline \multicolumn{5}{|c|}{ Percentage of errors in letter production } \\
\hline Alphabet* & $13.79(8.94)$ & $24.38(18.30)$ & $9.63(5.37)$ & $\mathrm{TD}<(\mathrm{D}=\mathrm{DCD})$ \\
\hline
\end{tabular}

Note: Means (standard deviations in parentheses) or median. $\mathrm{D}=$ dysgraphia; $\mathrm{DCD}=$ developmental coordination disorder; $\mathrm{TD}=$ typically developing group; wpm = words per minute; lpm = letters per minute.

${ }^{*} p \leq .050$.

\section{Handwriting speed}

One-way ANCOVAs (Group $\times$ Writing Task with age as covariate) revealed no significant effect of group for the alphabet task, as the three groups produced a similar number of letters during the one-minute task, $F(2,38)=1.92, p=.160, \eta^{2}=.092$. The covariate, age, was significantly related to the number of letters produced in the alphabet task, $F(1,38)=7.55, p<.009$, $\eta^{2}=.166$.

On the free-writing task there was a significant effect of group for the number of words written, $F(2$, 38) $=3.50, p=.040, \eta^{2}=.156$. Pairwise comparisons indicated that the TD group produced a higher number of words per minute than the dysgraphia $(p=.032)$ and DCD groups $(p=.024)$ who did not differ from each other $(p=.910)$. The covariate, age, was significantly related to the number of words produced, $F(2,38)=14.48, p<.001, \eta^{2}=.276$. See Table 2 for group means.

\section{Motor process 3: Muscular adjustment and real- time trajectory of pen}

\section{Execution speed}

The execution speed (the speed of the pen when it is in contact and moving on the page) for both groups averaged between 2 and $3 \mathrm{~cm} \mathrm{~s}^{-1}$ in both tasks. A two-way mixed ANCOVA (Group $\times$ Writing Task) was used to examine group differences across the two tasks. The co-variate age was significantly related to execution speed, $F(1,38)=14.61, p<.001, \eta^{2}=.278$. There was no effect of group, $F(2,38)=0.389, p$ $=.681, \eta^{2}=.020$, indicating that the three groups performed in a similar way. There was also no effect of task, $F(1,38)=2.38, p=.131, \eta^{2}=.59$ (degrees of freedom corrected for violation of sphericity with a Greenhouse-Geisser correction).

\section{Pausing percentage}

There was no group effect for the percentage of pausing on the alphabet task, $F(2,38)=0.599, p$ $=.554, \eta^{2}=.031$. However, there was a significant group effect for the free-writing task, $F(2,38)=4.93$, $p=.012, \eta^{2}=.206$. Pairwise comparisons indicated that the dysgraphia $(p=.016)$ and DCD $(p=.007)$ groups spent a significantly longer percentage of time pausing than their TD peers but did not differ from each other ( $p=.735$; see Table 2$)$.

\section{Performance profiles across the handwriting measures}

Tables 3 and 4 show the individual performance profiles of children in the dysgraphia and DCD groups, respectively. It can be seen that, within each group, children differ both in the severity of impairment and in the pattern of performance across the measures. Comparing the frequency of difficulties on the handwriting measures between the DCD and dysgraphia groups using chi-square tests of independence revealed no significant group differences. Based on 1 standard deviation, 7/14 (50\%) participants in the dysgraphia group had difficulties with handwriting speed, and 5/14 (36\%) participants in the DCD group, $X^{2}(2)=0.667, p=.717$. On the HLS $11 / 14$ (79\%) in the dysgraphia group were above (indicating 
Table 3. Performance profiles of children with dysgraphia across four measures.

\begin{tabular}{lcccc}
\hline & $\begin{array}{c}\text { Errors in letter } \\
\text { formation }^{\mathrm{a}} \\
(\%)\end{array}$ & $\begin{array}{c}\text { Speed } \\
(\text { wpm) } \\
\text { TD } M(S D) \\
=15.38 \\
\text { TD } M(S D)=\end{array}$ & $\begin{array}{c}\text { Legibility }^{\mathrm{a}}(\mathrm{HLS}) \\
\text { TD } M(S D)\end{array}$ & $\begin{array}{c}\text { Pausing }^{\mathrm{a}} \\
(\%)\end{array}$ \\
TD $M(S D)=$ \\
\hline 37 & $9.63(5.37)$ & $(4.48)$ & $9.07(2.06)$ & $53.52(8.70)$ \\
08 & -1 & -1 & -2 & 0 \\
10 & +2 & -1 & +4 & +2 \\
124 & +1 & +1 & +3 & 0 \\
133 & +3 & -2 & +3 & +1 \\
144 & +1 & 0 & +2 & +1 \\
45 & -2 & 0 & +2 & 0 \\
46 & +1 & 0 & +2 & +1 \\
147 & +1 & -1 & +2 & +1 \\
48 & +1 & +1 & +1 & -1 \\
49 & -1 & -2 & +1 & 0 \\
51 & +1 & -2 & +2 & +2 \\
156 & 0 & 0 & +1 & +1 \\
118 & -1 & 0 & 0 & 0 \\
\hline
\end{tabular}

Note: $\mathrm{HLS}=$ Handwriting Legibility Scale; TD = typically developing group; wpm $=$ words per minute. $0=$ within $1 S D$ of the TD mean.

${ }^{\text {a }}$ Positive $S D$ indicates performance below that of TD group.

poor performance) 1 standard deviation, and 12/14 $(86 \%)$ children in the DCD group, $X^{2}(2)=0.377, p$ $=.828$. For the percentage of pausing, $7 / 14(50 \%)$ children in the dysgraphia group were below their TD peers (showing greater pausing) and 9/14 (64\%) in children with $D C D, X^{2}(2)=1.74, p=.420$. For the percentage of errors in letterform production an equal number of children in the DCD and dysgraphia groups 9/14 (64\%) were at least 1 standard deviation below their TD peers on this measure, $X^{2}(2)=1.66$, $p=.435$ (see Table 5).

Table 4. Performance profiles of children in the DCD group across four measures.

\begin{tabular}{lcccc}
\hline & $\begin{array}{c}\text { Errors in letter } \\
\text { formation }^{\mathrm{a}} \\
(\%)\end{array}$ & $\begin{array}{c}\text { Speed } \\
(\text { wpm) } \\
\text { TD } M(S D) \\
=15.38\end{array}$ & $\begin{array}{c}\text { Legibility }^{\mathrm{a}}(\mathrm{HLS}) \\
\text { TD } M(S D)=\end{array}$ & $\begin{array}{c}\text { Pausing }^{\mathrm{a}} \\
(\%)\end{array}$ \\
TD $M(S D)=$ & $(S D)=$ \\
Participant & $9.63(5.37)$ & $(4.48)$ & $9.07(2.06)$ & $53.52(8.70)$ \\
\hline 02 & +6 & -1 & +3 & +2 \\
05 & +8 & +1 & +3 & -1 \\
15 & +7 & -1 & +7 & +1 \\
18 & 0 & 0 & +1 & +1 \\
19 & +1 & 0 & +1 & +1 \\
20 & +1 & 0 & +2 & 0 \\
28 & +1 & -1 & +1 & +1 \\
24 & +1 & 0 & +1 & +1 \\
30 & -1 & +2 & 0 & -1 \\
39 & +9 & -2 & +2 & +1 \\
33 & 0 & 0 & +2 & +2 \\
41 & 0 & -1 & +2 & 0 \\
42 & -1 & 0 & -1 & -1 \\
53 & +3 & 0 & +1 & +1 \\
\hline
\end{tabular}

Note: $\mathrm{DCD}=$ developmental coordination disorder; $\mathrm{HLS}=$ Handwriting Legibility Scale; TD = typically developing group; $w p m=$ words per minute. $0=$ within $1 S D$ of the TD mean.

${ }^{\text {a }}$ Positive $S D$ indicates performance below that of TD group. ${ }^{*} p \leq .050$.
In relation to the severity of difficulties, chi-square tests of independence revealed no significant group differences. For example, for the quality of letter formation, while 5/14 (35\%) children in the DCD group appeared to score between 3 and 9 standard deviations below the TD group mean compared to $2 / 14$ (14\%), this was not significant, $\chi^{2}(3)=3.21, p=.360$.

\section{Results across measures}

Out of the 14 children with DCD, 12/14 (86\%) were poor on at least two measures with four of them (29\%) scoring below 1 standard deviation on all four measures followed by three (21\%) across three measures. Only two (14\%) children with DCD scored within the TD range on all measures. Similar profiles emerged in the dysgraphia group with 11/14 (79\%) poor on at least two measures, $4 / 14(29 \%)$ on four, and 2/14 (14\%) on three. Tables 3 and 4 indicate the performance profiles of the DCD and dysgraphia groups on the four measures.

\section{Correlations with vocabulary, reading, spelling, and motor measures}

Partial correlations (controlling for age) conducted on each group separately revealed no significant relationships between any of the literacy measures (vocabulary, reading, spelling, manual dexterity) and the handwriting measures (quality of letter formation, handwriting speed, legibility, execution speed, and pausing). When conducted with all participants together there were significant relationships between spelling, vocabulary, and manual dexterity with some of the handwriting measures. For example, poorer letter formation and overall legibility were associated with both poorer spelling and poorer manual dexterity. Faster writing was associated with

Table 5. Percentage of children in the dysgraphia and DCD groups with scores below 1 standard deviation of TD group mean.

\begin{tabular}{lccc}
\hline Measure & TD & $\begin{array}{c}\text { Dysgraphia } \\
(\%)\end{array}$ & $\begin{array}{r}\text { DCD } \\
(\%)\end{array}$ \\
\hline Speed (wpm) & $M(S D)$ & 50 & 36 \\
Legibility (HLS) & $15.38(4.48)$ & 79 & 86 \\
$\%$ Pausing & $9.07(2.06)$ & 50 & 64 \\
\% Errors in letter formation & $53.52(8.70)$ & 64 & 64 \\
\hline Note: Standard deviations in parentheses. DCD = developmental coordination \\
disorder; HLS = Handwriting Legibility Scale; TD = typically developing \\
group; wpm = words per minute.
\end{tabular}


Table 6. Correlations between reading, spelling, vocabulary, and manual dexterity with the handwriting measures.

\begin{tabular}{|c|c|c|c|c|c|c|c|c|}
\hline \multirow[b]{2}{*}{ Measure } & \multicolumn{2}{|c|}{ Reading } & \multicolumn{2}{|c|}{ Spelling } & \multicolumn{2}{|c|}{ Vocabulary } & \multicolumn{2}{|c|}{ Manual dexterity } \\
\hline & $r$ & $p$ & $r$ & $p$ & $r$ & $p$ & $r$ & $p$ \\
\hline $\begin{array}{l}\text { Quality of letter formation } \\
\text { (\% incorrect letter forms) }\end{array}$ & -.309 & .067 & -.383 & $.021^{*}$ & -.033 & .846 & -.351 & $.036^{*}$ \\
\hline Free writing (wpm) & .079 & .648 & .322 & .056 & -.409 & $.013^{*}$ & .262 & .123 \\
\hline HLS total score $(1-25)^{\mathrm{a}}$ & -.276 & .103 & -.397 & $.017^{*}$ & .261 & .125 & -.658 & $<.001^{*}$ \\
\hline Execution speed $\left(\mathrm{cms}^{-1}\right)$ & .123 & .477 & .155 & .367 & -.093 & .590 & -.112 & .515 \\
\hline$\%$ Pausing on free writing & -.099 & .565 & -.361 & $.031^{*}$ & .367 & $.028^{*}$ & -.399 & $.016^{*}$ \\
\hline
\end{tabular}

Note: $N=42$. HLS = Handwriting Legibility Scale; $w p m=$ words per minute

${ }^{a}$ Higher scores on HLS reflect poorer legibility.

${ }^{*} p \leq .050$.

poorer vocabulary, and more pausing in the writing was associated with poorer manual dexterity, vocabulary, and spelling. There were no significant correlations with reading ability (see Table 6).

\section{Discussion}

Previous research on handwriting has focused on identifying performance deficits in groups of children with different developmental disorders (Adi-Japha et al., 2007; Connelly et al., 2012; Prunty et al., 2013; Rosenblum et al., 2008; Sumner et al., 2014). However, there are many children who have significant handwriting difficulties in the absence of specific developmental disorders (Di Brina et al., 2008; Dohla \& Heim, 2015; Rosenblum et al., 2003; Smits-Engelsman \& Schoemaker, 2017). Often referred to as dysgraphia, this particular group causes concern to teachers and can severely impact on progress for the children. While work has been done on understanding handwriting difficulties in atypically developing children, this particular group has not received as much attention in the literature. As a consequence, it is unclear how they differ from other groups of children and how best to support them in school.

Using a range of measures accessible to health and educational professionals to help understand different aspects of performance, we examined handwriting in children with dysgraphia compared to children with and without DCD. In doing so we took into consideration additional factors that might impact on handwriting performance such as motor coordination, language, reading, and spelling skill. Our findings generally reflect those of Smits-Engelsman and Schoemaker (2017) who compared the performance of children with dysgraphia and DCD on a drawing task and found no group differences. This pattern held for the comprehensive range of measures used in our study, examining aspects of both the product and process of handwriting, considering both temporal features and the quality/accuracy of letter formation. This was an interesting finding as none of the children in the dysgraphia group had a significant motor difficulty, all with scores above the 16th percentile on the MABC- 2 (and scores on the Manual Dexterity component in the average range for their age). It seems that despite the extensive range of measures used in this study we were unable to clearly distinguish between the dysgraphia and DCD groups. Both the DCD and dysgraphia groups displayed difficulties across the range of measures in comparison to the TD controls, including handwriting speed, legibility, and the handwriting process measures (pausing and letter formation).

The three motor processes outlined in Van Galen's (1991) model serve as a useful lens for discussion as we used the model as a framework for investigation. However, as there are no clinical tools specifically designed to assess each of these, we attempted to align our clinical assessments to this model. We recognize that there are limitations to this as while the measures align to some degree with the motor processes outlined by Van Galen (1991), the alignment is not perfect, and each measure probably reflects processing at several levels. Nonetheless the first process examined was the selection of the allograph, which we evaluated through studying the quality of letter formation in real time. We considered that poor letter formation might reflect poor knowledge about the proper form of the allograph. Previous studies such as Di Brina et al. (2010) reported inaccuracy of letter formation using single letters in children with dysgraphia. However, in the current study we were interested in identifying letters across the alphabet that were formed in a way that would not be taught in schools. Interestingly the DCD and dysgraphia 
groups had an equal percentage of children with difficulties in this area (64\%). As such, it would appear that both groups align with previous descriptions of poor writers where a higher percentage of inaccurate letter forms were reported compared to TD peers ( $\mathrm{Di}$ Brina et al, 2010; Smits-Engelsman \& Van Galen, 1997). However, it is difficult to speculate on the underlying mechanisms for this issue in both groups as while deficits in motor sequence learning and procedural learning may be an issue in the DCD group (Bo et al, 2014; Wilson, Ruddock, Smits-Engelsman, Polatajko, \& Blank, 2013), this has yet to be examined in children with dysgraphia. Indeed the considerable variation in performance on this measure adds another layer of complexity as while some children appeared to be more severely affected than others (3-9 SDs below TD group mean), there were five children in both groups who did not appear to have any difficulties on this measure. However, the allograph is only one level of analyses. According to Di Brina et al (2010) the inaccuracy of letterforms reported in their dysgraphia group was independent of difficulties with size control (in their case trajectory length and velocity). As such, the process of size control (parameterization), which was the second area of consideration in this study, may provide more insight.

To examine the motor process of size/speed control we used measures of handwriting speed and legibility. Size control here refers to the parameterization of the motor programme where the size, speed, and spacing of allographs are programmed (Van Galen, 1991). Looking at the individual data it seems that both the dysgraphia and DCD groups demonstrated significant difficulties with parameterization evident through a high percentage of children in each group with difficulties on the HLS. The HLS examines aspects of legibility including the size and spacing within and between words. Pending the correct sequencing of strokes at the allograph level, paramaterization would be a key factor, which could impact on global legibility as measured by the HLS. Interestingly, both groups had difficulties with handwriting speed as measured through the number of words produced per minute. However, many factors could contribute to this finding including higher level cognitive processes such as planning (Berninger \& Swanson, 1994), and as such it may not be exclusively an issue with motor processing. Looking at the individual data on handwriting speed, $50 \%$ of the dysgraphia group had difficulties, compared to $36 \%$ in the DCD group. However, this difference was not significant. The issue of heterogeneity within the groups was again apparent, and it remains unclear why some children within either group had difficulties writing quickly while others did not.

The final motor process in Van Galen's (1991) model is the recruitment of muscle synergies, which results in the real-time movement of the pen. While physiological examinations of muscle activation and recruitment (i.e., electromyography/biofeedback) were beyond the scope of this study, we examined the execution speed of the pen and the percentage of pausing during writing to identify slowness and dysfluency in the real-time movement of the pen. Interestingly both the dysgraphia and DCD groups did not differ from the TD group on execution speed, indicating that they were able to move the pen as quickly as their peers. However, both the DCD and dysgraphia groups paused for a greater percentage of the task, indicating some dysfluency in the movement of the pen. According to Smits-Engelsman and Van Galen (1997), this motor process includes muscular initiation, which can be impacted by neuromotor noise in children with handwriting difficulties. While we did not consider the control of movement beyond measures of manual dexterity and execution speed of the pen, an examination at this level could help differentiate between children with dysgraphia and DCD. Indeed Smits-Engelsman and Van Galen (1997) suggested that poor writers are unable to adapt their fine distal musculature movements to the demands of an accurate handwriting task. Furthermore, it has been hypothesized that children with handwriting difficulties are unable to apply effective biomechanical strategies such as "stiffness" to reduce neuromotor noise (Van Galen \& De Jong, 1995; Van Galen, Portier, Smits-Engelsman, \& Schomaker, 1993). According to Smits-Engelsman and Wilson (2013), neuromotor noise involves unpredictable fluctuations and disturbances during movement, which can have a neural, neuromuscular, or environmental origin. The inability to apply movement strategies to counteract noise in the system may result in crude movements, which according to Van Galen et al. (1993) have an impact on the quality of handwriting. These crude movements described by Van Galen et al (1993) align with the idea that poor writers resort to using the wrist or the elbow as pivots of action. This may result in 
larger movements, which are not conducive to accurate performance on a task such as handwriting (Smits-Engelsman \& Van Galen, 1997). However, while there are some hypotheses in the literature surrounding neuromotor noise and the biomechanical influences, these were outside the scope of this study. Further research is needed to investigate the process of muscular adjustment in more detail to examine possible differences between handwriting difficulties in dysgraphia and DCD.

A limitation of this study was the relatively small sample size, which may have impacted on power and overall null group differences. If supported in larger studies, these findings suggest that it may be helpful to include other groups of children such as those with dyslexia and specific language impairment, to begin to understand the nature of handwriting difficulties in these different groups. Full diagnostic assessment is important to differentiate the groups and should include a range of literacy and motor measures that may impact on handwriting production. Although our samples were too small to identify any significant relationships between measures within each of the groups, some significant correlations were found when we considered all groups together. For example, better manual dexterity scores and better spelling scores were each associated with better letter formation/legibility and less pausing during writing. This seems to reflect the importance of manual dexterity and spelling ability to aspects of handwriting production. Some other correlations are more difficult to interpret and need further investigation. A further limitation of our work is that, while we applied Van Galen's (1991) model as a framework for investigation, our clinical measures were not specifically designed to tap into these processes. Nonetheless, the extensive range of measures used allowed us to gain greater insight into the heterogeneity and presentation of handwriting difficulties in children with dysgraphia. The within-group variability found across the measures showed that no one assessment was able to capture every child with a handwriting difficulty. This suggests that in both research and clinical practice a range of measures needs to be included to more fully understand handwriting profiles. In addition, one area that was not considered in this study was the influence of external factors such as the way in which handwriting is taught in the schools of the participants and the amount of handwriting practice they engaged in (Molyneaux, Barnett, Glenny, \& Davies, 2013; SmitsEngelsman \& Van Galen, 1997). These are societalbased factors, which were outside the scope of this study but do warrant further investigation.

In summary, our examination of handwriting performance in children with dysgraphia spanned across the three motor processes of Van Galen's (1991) model and found that children in this group had difficulties in all three areas. Further work needs to be done to understand these processes in more detail as despite poor performance at a group level on all of our clinical measures, the individual variability within and across the measures illustrates the complex nature of handwriting difficulties. The results advance our knowledge of handwriting difficulties in children with dysgraphia but more research is needed in order to understand the underlying mechanisms of their difficulties. Further research needs to unpick the motor processes in more detail to aid in the provision of evidence for planning future interventions in this group.

\section{Note}

1. In the literature the term "allograph" is used in different ways including to describe the visual (non-motor) representation of a letter (Teulings, 1996). The present study uses Van Galen's (1991) definition.

\section{Acknowledgements}

We would like to thank all of the participants, their families, and the schools who took part in this study.

\section{Disclosure statement}

No potential conflict of interest was reported by the authors.

\section{ORCID}

Mellissa Prunty (D) http://orcid.org/0000-0001-5149-9153

\section{References}

Adi-Japha, E., Landau, Y., Frenkel, L., Teicher, M., Gross-Tsur, V., \& Shalev, R. (2007). ADHD and dysgraphia: Underlying mechanisms. Cortex, 43(6), 700-709.

Alamargot, D., Chesnet, D., Dansac, C., \& Ros, C. (2006). Eye and Pen: A new device for studying reading during writing. Behavior Research Methods, 38(2), 287-299. 
American Psychiatric Association (APA). (2013). DSM-5. Diagnostic and statistical manual of mental disorders (5th ed.). Washington: American Psychiatric Association.

Barnett, A., Henderson, S., Scheib, B., \& Schulz, J. (2007). The detailed assessment of speed of handwriting. London: Harcourt Assessment.

Barnett, A., Prunty, M., \& Rosenblum, S. (2013, June). Development of the handwriting legibility scale (HLS): An examination of reliability and validity. Paper presented at the International Graphonomics Society Conference, Nara, Japan.

Berninger, V., Abbott, R., Abbott, S., Graham, S., \& Richards, T. (2002). Writing and reading: Connections between language by hand and language by eye. Journal of Learning Disabilities, 35, 39-56.

Berninger, V., \& Swanson, L. (1994). Modifying Hayes \& Flower's model of skilled writing to explain beginning and developing writing. In E. Butterfield (Ed.), Children's writing: Toward a process theory of development of skilled writing (pp. 5781). Greenwich, CT: JAI Press.

Blank, R., Smits-Engelsman, B., Polatajko, H., \& Wilson, P. (2012). European academy for childhood disability (EACD): Recommendations on the definition, diagnosis and intervention of developmental coordination disorder (long version). Developmental Medicine and Child Neurology, 54(1), 54-93.

Bo, J., Colbert, A., Lee, C., Schaffert, J., Oswald, K., \& Neill, R. (2014). Examining the relationship between motor assessments and handwriting consistency in children with and without probable developmental coordination disorder. Research in Developmental Disabilities, 35(9), 2035-2043.

Cascio, W. F., Alexander, R. A., \& Barrett, G. V. (1988). Setting cutoff scores: Legal, psychometric, and professional issues and guidelines. Personnel Psychology, 41(1), 1-24.

Connelly, V., \& Dockrell, J. (2015). The role of oral language in underpinning the text generation difficulties in children with specific language impairment. Journal of Research in Reading, 38(1), 18-34.

Connelly, V., Dockrell, J., Walter, K., \& Critten, S. (2012). Predicting the quality of composition and written language bursts from oral language, spelling and handwriting skills in children with and without specific language impairment. Written Communication, 29, 278-302.

Department for Education (DfE). (2013). The national curriculum in England. Retrieved March 2017, from https://www.gov.uk/ government/collections/national-curriculum

Di Brina, C., Niels, R., Overvelde, A., Levi, G., \& Hulstijn, W. (2008). Dynamic time warping: A new method in the study of poor handwriting. Human Movement Science, 27(2), 242-255.

Dohla, D., \& Heim, S. (2015). Developmental dyslexia and dysgraphia: what can we learn from the one about the other? Frontiers in Psychology, 6(2045). 10.3389/fpsyg.2015.02045

Dunn, L., Dunn, L., Whetton, C., \& Burley, J. (1997). The British picture vocabulary scale (2nd ed.). London: NFER Nelson Publishing Company Ltd.

Elliot, C. (1996). British ability scales (II): Administration and scoring manual. London: NFER Nelson Publishing Company Ltd.

Engel-Yeger, B., Nagauker-Yanuv, L., \& Rosenblum, S. (2009). Handwriting performance, self-reports, and perceived self- efficacy among children with dysgraphia. American Journal of Occupational Therapy, 63, 182-192.

Glenn, S., \& Cunningham, C. (2005). Performance of young people with Down syndrome on the Leiter-R and British picture vocabulary scales. Journal of Intellectual Disability Research, 49, 239-244.

Goodman, R. (1997). The strengths and difficulties questionnaire: A research note. Journal of Child Psychology and Psychiatry, 38, 581-586.

Graham, S., Berninger, V., Abbott, R., Abbott, S., \& Whitaker, D. (1997). Role of mechanics in composing of elementary school students: A new methodological approach. Journal of Educational Psychology, 89, 170-182.

Graham, S., Berninger, V., Weintraub, N., \& Schafer, W. (1998). Development of handwriting speed and legibility in grades 1-9. The Journal of Educational Research, 92(1), 42-52.

Graham, S., Harris, K., \& Fink, B. (2000). Is handwriting causally related to learning to write? Treatment of handwriting problems in beginning writers. Journal of Educational Psychology, 92, 620-633.

Henderson, S., Sugden, D., \& Barnett, A. (2007). Movement assessment battery for children (2nd ed). (Movement ABC-2). Examiner's Manual. London: Pearson Assessment.

Kandel, S., Soler, O., Valdois, S., \& Gros, C. (2006). Graphemes as motor units in the acquisition of writing skills. Reading and Writing, 19, 313-337.

Lambert, E., Kandel, S., Fayol, M., \& Esperet, E. (2008). The effect of the number of syllables on handwriting production. Reading and Writing, 21, 859-883.

Miceli, G., \& Capasso, R. (2006). Spelling and dysgraphia. Cognitive Neuropsychology, 23(1), 110-134.

Miller, L., Missiuna, C., Macnab, J., Malloy-Miller, T., \& Polatajko, H. (2001). Clinical description of children with developmental coordination disorder. Canadian Journal of Occupational Therapy, 68, 5-15.

Molyneaux, A., Barnett, A., Glenny, G., \& Davies, R. (2013, June). The association between handwriting practice and lexical richness: An analysis of the handwritten output of children aged 910 years. Paper presented at the International Graphonomics Society Conference, Nara, Japan.

Prunty, M., \& Barnett, A. (2017). Accuracy and consistency of letter formation in children with developmental coordination disorder. Journal of Learning Disabilities, Manuscript submitted for publication.

Prunty, M., Barnett, A., Wilmut, K., \& Plumb, M. (2013). Handwriting speed in children with developmental coordination disorder: Are they really slower? Research in Developmental Disabilities, 34(9), 2927-2936.

Prunty, M., Barnett, A., Wilmut, K., \& Plumb, M. (2014). An examination of writing pauses in the handwriting of children with developmental coordination disorder. Research in Developmental Disabilities, 35(11), 2894-2905.

Prunty, M., Barnett, A., Wilmut, K., \& Plumb, M. (2016). The impact of handwriting difficulties on compositional quality in children with developmental coordination disorder. British Journal of Occupational Therapy, 79(10), 591-597. 
Puranik, C. S., \& Al Otaiba, S. (2012). Examining the contribution of handwriting and spelling to written expression in kindergarten children. Reading and Writing, 25, 1523-1546.

Rapp, B., Purcell, J., Hillis, A., Capasso, R., \& Miceli, G. (2016). Neural bases of orthographic long-term memory and working memory in dysgraphia. Brain, 139(2), 588-604.

Rosenblum, S., Epsztein, L., \& Josman, N. (2008). Handwriting performance of children with attention deficit hyperactive disorders: A pilot study. Physical \& Occupational Therapy in Pediatrics, 28(3), 219-234.

Rosenblum, S., \& Livneh-Zirinski, M. (2008). Handwriting process and product characteristics of children diagnosed with developmental coordination disorder. Human Movement Science, 27(2), 200-214.

Rosenblum, S., Parush, S., \& Weiss, P. (2003). Computerized temporal handwriting characteristics of proficient and non-proficient handwriters. American Journal of Occupational Therapy, 57(2), 129-138.

Smits-Engelsman, B., \& Schoemaker, M. (2017). Comparability of graphic performance in children with pure dysgraphia and children with dysgraphia as part of developmental coordination disorder (DCD). In A. L. Barnett, \& D. A. Sugden (Eds.), Moving, developing and learning. A Festschrift in celebration of the career of Sheila E. Henderson (pp. 81-95). Oxford: Oxford Brookes University.

Smits-Engelsman, B., \& Van Galen, G. (1997). Dysgraphia in children: Lasting psychomotor deficiency or transient developmental delay? Journal of Experimental Child Psychology, 67 (2), 164-184.

Smits-Engelsman, B., \& Wilson, P. (2013). Noise, variability, and motor performance in developmental coordination disorder. Developmental Medicine \& Child Neurology, 55(4), 69-72.
Sugden, D., \& Chambers, M. (2007). Stability and change in children with developmental coordination disorder. Child: Care, Health and Development, 33(5), 520-528.

Sumner, E., Connelly, V., \& Barnett, A. (2013). Children with dyslexia are slow writers because they pause more often and not because they are slow at handwriting execution. Reading and Writing, 26(6), 991-1008.

Sumner, E., Connelly, V., \& Barnett, A. (2014). The influence of spelling ability on handwriting production: Children with and without dyslexia. Journal of Experimental Psychology: Learning, Memory, and Cognition, 40(5), 1441-1447.

Teulings, H. L. (1996). Handwriting movement control. In S. W. Keele, \& H. Heuer (Eds.), Handbook of perception and action. Vol.2: Motor skills (pp. 561-613). London: Academic Press. ISBN 0-12-516162-X (reformatted).

Van Galen, G., \& De Jong, W. (1995). Fitts' law as the outcome of a dynamic noise filtering model of motor control. Human Movement Science, 14(4-5), 539-571.

Van Galen, G. (1991). Handwriting: Issues for a psychomotor theory. Human Movement Science, 10, 165-191.

Van Galen, G., Portier, S. J., Smits-Engelsman, B., \& Schomaker, L. (1993). Neuromotor noise and poor handwriting in children. Acta Psychologica, 82, 161-178.

Van Hartingsveldt, M., De Groot, I., Aarts, P. B., \& Nijhuis-Van Der Sanden, M. W. (2011). Standardized tests of hand-writing readiness: A systematic review of the literature. Developmental Medicine \& Child Neurology, 53, 506-515.

Wilson, P., Ruddock, S., Smits-Engelsman, B., Polatajko, H., \& Blank, R. (2013). Understanding performance deficits in developmental coordination disorder: A meta-analysis of recent research. Developmental Medicine \& Child Neurology, 55(3), 217-228. 